\title{
PERFORMANCE BASED DESIGN OF UNBRACED STEEL FRAMES EXPOSED TO NATURAL FIRE SCENARIOS
}

\author{
Carlos Couto $^{\mathrm{a}}$, Thiago Silva ${ }^{\mathrm{a}}$, Martina Carić ${ }^{\mathrm{b}}$, Paulo Vila Real ${ }^{\mathrm{a}}$, Davor Skejićc \\ ${ }^{a}$ RISCO - Department of Civil Engineering, University of Aveiro, Portugal \\ ${ }^{\mathrm{b}}$ University of Zagreb, Faculty of Civil Engineering, Croatia
}

\begin{abstract}
According to the Eurocode 3 Part 1-2 (EN1993-1-2) (CEN 2005b), it is possible for structural engineers to consider physical based thermal actions and to do performance based design instead of using prescriptive rules based on nominal fire curves. However, some uncertainties remain in the use of such approaches. This study focus on the clarification of the use of the simplified design methods to assess the fire resistance of unbraced steel frames exposed to fire. On the other hand, a recent study (Couto et al. 2013) suggests the use of a buckling coefficient of 1.0 for all the columns except those belonging to the first storey of a pinned framed where 2.0 should be taken instead and it is unclear if the consideration of such values for the buckling lengths is adequate when using performance based designs.

In this study, a comparison is made between simple and advanced calculation models and it is demonstrated that the simple design methods, using the suggested buckling coefficients to calculate the fire resistance of the frames are safe sided when compared to the use of advanced calculations using the finite element method (FEM).
\end{abstract}

Keywords: structural fire design; unbraced steel frames; buckling; natural fire; performance based design

\section{INTRODUCTION}

For actions on structures exposed to fire, Eurocode 3 Part 1-2 (CEN 2005b) makes a distinction between nominal temperature-time curves, on one hand, and natural fire models on the other hand. Nominal curves are not supposed to represent a real fire, they are considered as conventional curves, while parametric curves are analytic functions that give the evolution of the gas temperature in a compartment as a function of time based on physical parameters that represent the most important variables that influence the development of the fire in the compartment. For structural fire design, Eurocode 3 Part 1-2 states that for verifying standard fire resistance requirements, a member analysis is sufficient, but no reference is given when using parametric fire.

To determine the fire resistance of steel frames, two design methods are permitted according to EN1993-1-2: simplified calculation methods - for individual members based on conservative assumptions, and advanced calculation methods - which provide a realistic analysis of structures exposed to fire and they are based on fundamental physical behaviour.

Furthermore, when using the simplified design methods, the EN1993-1-2 states that in the case of a braced frame in which each storey comprises a separate fire compartment with sufficient fire resistance, the buckling length, $l_{f i}$, of a continuous column may be taken as $0.5 \mathrm{~L}$ in an intermediate storey, where $L$ is the system length in the relevant storey. For unbraced frames, Eurocode does not give specific guidance (Vila Real et al. 2010) and studies on the buckling analysis of unbraced steel frames exposed to fire (Couto et al. 2013) led to a proposal of $1.0 \mathrm{~L}$ as the buckling length of all columns except those belonging to the first storey of a pinned frame where $2.0 \mathrm{~L}$ should be taken instead. However, only the nominal fire curve was considered in that study and it is unclear if those values are adequate for natural fire models. Another study (Xu and Zhuang, 2014) investigated the behaviour of a single-storey and two-bay unbraced frame subjected to different fire scenarios including localized ones with the results suggesting that fire spreading from one room to another shortly after the fire was ignited in one room will do more harm to frame stability. 
Finally, in this paper, several unbraced frames are analysed for the case of fire, taking into account the effect of temperature. Both the nominal and natural (parametric) fires were considered and simple and advanced methods were employed to calculate the fire resistance of the frames. It is demonstrated that the simple design methods, together with the buckling lengths proposed by (Couto et al. 2013), could be used to check the fire resistance of a steel frame exposed to a natural fire (parametric fire curve) since results in favour of the safety are obtained when compared to advanced models.

\section{MATERIALS AND METHODS}

In this research, three frames were analysed as shown in Fig. 1. The frames were considered with fixed and pinned supports and with rigid connections between beams and columns. First the structure was designed at room temperature. Then, its fire resistance was assessed with the simplified methods from the EN 1993-1-2 and compared to the resistance given by the finite element method (FEM). In both cases verifications for nominal (ISO834) and natural fire were performed.

\subsection{Methodology used in the design of the structure}

The structural analysis was performed using the software SAP 2000 (Computers and Structures 1995), considering the effects of second order $(\mathrm{P}-\Delta)$ and global imperfections as well as the values of the actions and combinations according to Eurocode (CEN 2002a; CEN 2002b). Additionally, in all combinations for the ultimate limit state horizontal forces were included due to global imperfections of the frame (CEN 2005a). The member design was performed in the elastic range considering the buckling coefficient of the members equal to one $\left(l_{c r} / l=1.0\right)$ in accordance with the EN 1993-1-1 (CEN 2005a). The columns are of HEB type and the beams are of IPE type with S355 steel grade $\left(f_{y}=355 \mathrm{MPa}\right.$ and $\left.E=210 \mathrm{GPa}\right)$, as shown in Fig. 1.
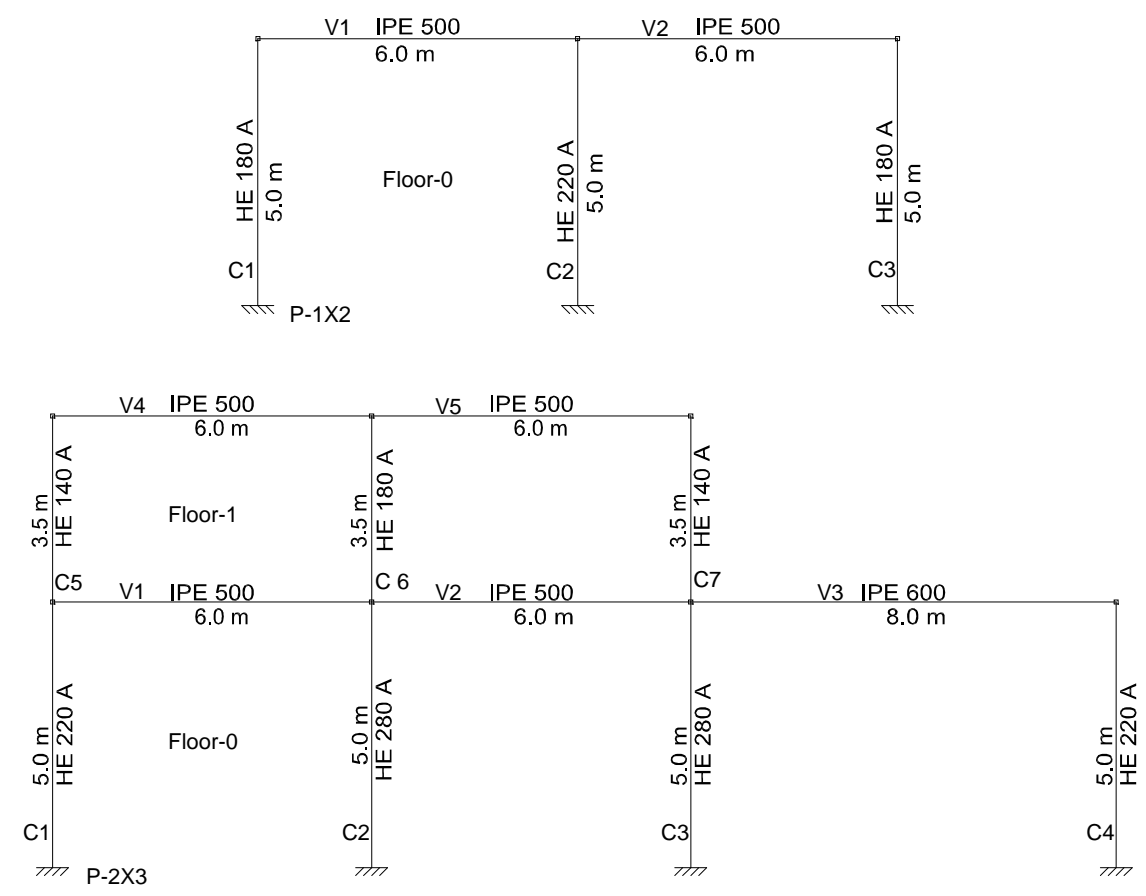


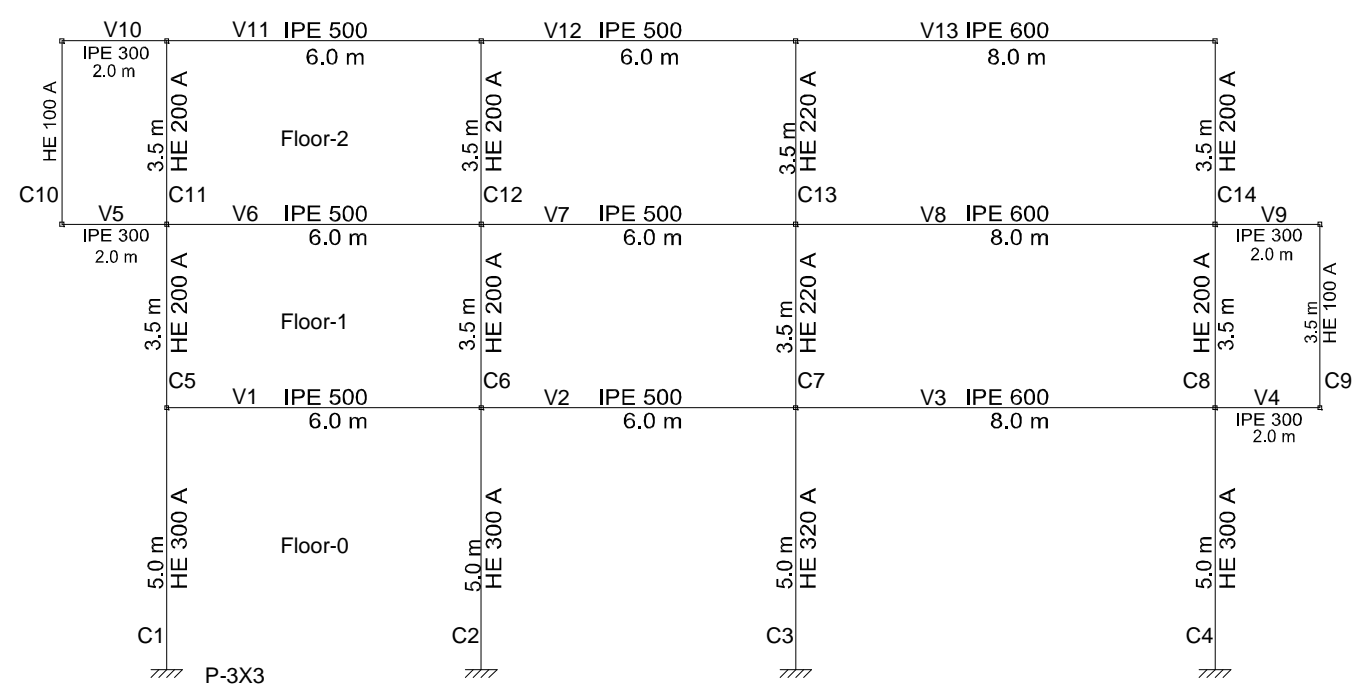

Fig. 1 Frames geometries and cross-sections (dimensions in meters).

\subsection{Methodology used in fire situation}

It was considered that the external columns and beams were heated on 3 sides and the internal columns were heated on 4 sides, as shown in Fig. 2. Table 1 presents the area of the floors and the openings that was used to determine the evaluation of the temperature of the compartments in natural fire. It was considered that the buildings were used as offices, with walls made with normal bricks and reinforced concrete slab with $20 \mathrm{~cm}$ thick.

Fire was considered at each floor separately according to ISO834 fire curve and for fixed and pinned frames. However, for the natural fire two different fire scenarios were considered: only half of the floor area under fire and also fire in the whole area of floor. The temperature evolution in two different cross-sections for the ISO834 and natural fire is shown in Fig. 3.

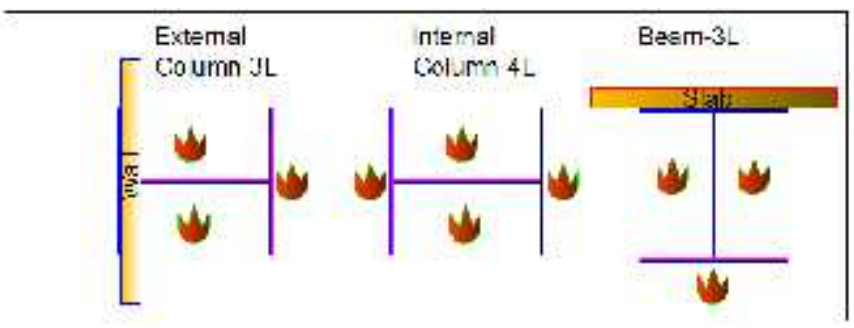

Fig. 1 Fire situation.
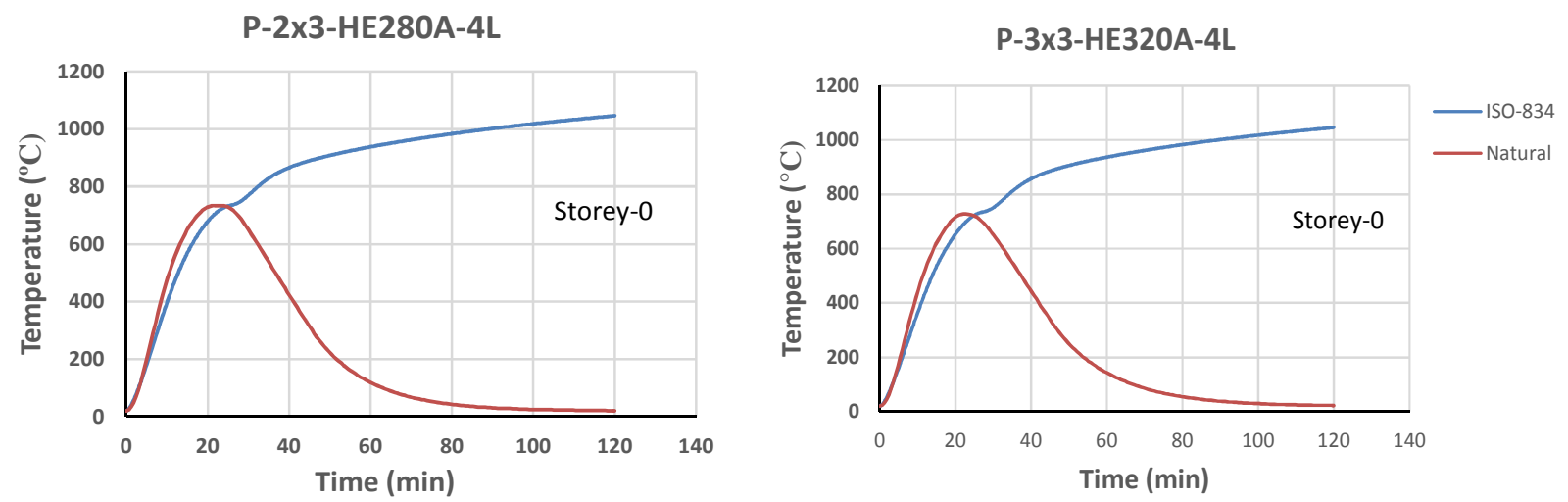

Fig. 2 Comparison of the temperatures in two cross-sections (columns) with the nominal fire curve and natural fire. 
Table 1 Areas of floors and openings used in determining the temperature of the environment for the natural fire.

\begin{tabular}{|c|c|c|c|c|c|c|c|}
\hline \multirow{3}{*}{ Frame } & \multirow{3}{*}{ Scenario } & \multicolumn{2}{|c|}{ Storey-0 } & \multicolumn{2}{|c|}{ Storey-1 } & \multicolumn{2}{|c|}{ Storey-2 } \\
\hline & & \multicolumn{2}{|c|}{ Areas $\left[\mathrm{m}^{2}\right]$} & \multicolumn{2}{|c|}{ Areas $\left[\mathrm{m}^{2}\right]$} & \multicolumn{2}{|c|}{ Areas $\left[\mathrm{m}^{2}\right]$} \\
\hline & & Floor & Openings & Floor & Openings & Floor & Openings \\
\hline \multirow{2}{*}{$\mathrm{P}-1 \mathrm{x} 2$} & 1 & 59.6 & 18 & - & - & - & - \\
\hline & 2 & 120.6 & 36 & - & - & - & - \\
\hline \multirow{2}{*}{$\mathrm{P}-2 \times 3$} & 1 & 142.32 & 38 & 152.14 & 46 & - & - \\
\hline & 2 & 280.11 & 86 & - & - & & - \\
\hline \multirow{2}{*}{$P-3 \times 3$} & 1 & 142.32 & 38 & 142.32 & 38 & 142.32 & 41 \\
\hline & 2 & 280.11 & 86 & 280.11 & 83 & 280.11 & 83 \\
\hline
\end{tabular}

Two different methodologies were used for the verification of steel structures in a fire situation. Firstly, the fire resistance time was calculated with simplified methods using the formulations proposed by EN1993-1-2. This verification was conducted with software Elefir-EN (Vila Real \& Franssen 2011), developed at the University of Aveiro. Secondly, the structure was verified with advanced calculation methods, by performing Geometrically and Material Non-Linear Analysis (GMNIA) using the finite element method (FEM) software SAFIR (Franssen 2005), developed at the University of Liège. For both cases the thermal analysis was based on the standard fire curve ISO 834 and the parametric curves (natural fire).

In verification with the simplified method $1^{\text {st }}$ order analysis was considered, with buckling coefficients equal to those proposed by (Couto et al. 2013), since the EN1993-1-2 does not mention any values for columns belonging to unbraced frames. Accordingly, for unbraced frames, with fixed and pinned supports, the buckling coefficient for columns were considered equal to 1.0, except for the columns on the first floor for frames with pinned supports where a buckling coefficient equal to 2.0 was adopted.

\section{RESULTS AND DISCUSSION}

Fig. 4 shows the evolution of the elastic critical load of the frames $\left(\alpha_{\text {cr,fi }}\right)$ with the temperature considering a fire in the first storey which comprises the most critical case. It is observed that during the heating phase for both the ISO834 and the natural fire the values are superimposed and small differences are identified in the cooling phase of the natural fire. Fig. 5 shows the evolution of the buckling length with the temperature following the same methodology as in (Couto et al. 2013) following the same conclusions highlighted for the variation of the elastic critical load.
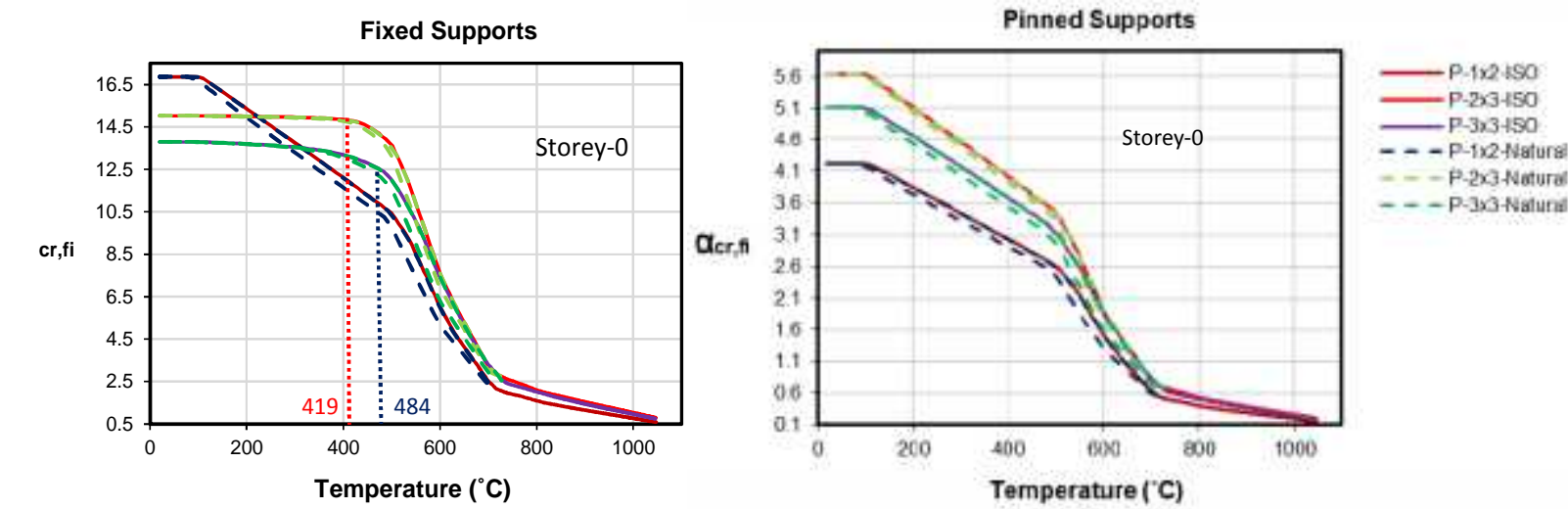

Fig. 3 Evolution of the critical load with the temperature with the nominal and natural fire curve. 

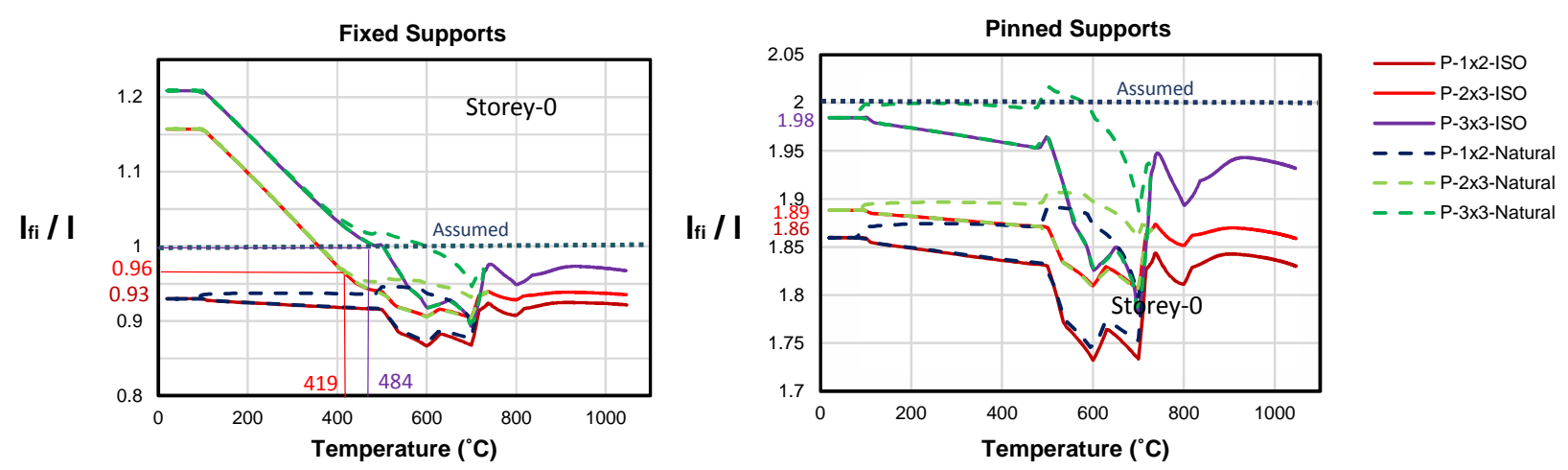

Fig. 4 - Variation of the buckling length of the columns of an unbraced frame with the nominal and natural fire curve.

Regarding the values proposed in (Couto et al. 2013) for the buckling lengths, which were derived based on the nominal fire curve ISO834, Fig. 5 shows that those values are valid also for the natural fire and were used in the remaining part of this study.

At this point, the results obtained by comparing the simplified methods and advanced calculation methods for verification the fire of the analysed frames are presented, taking into account the different methodologies presented in Section 2. The distinction is made between Scenarios 01 and 02 (SC-1 and SC-2) and where the fire was considered in each storey (storey 0, storey 1 and storey 2).
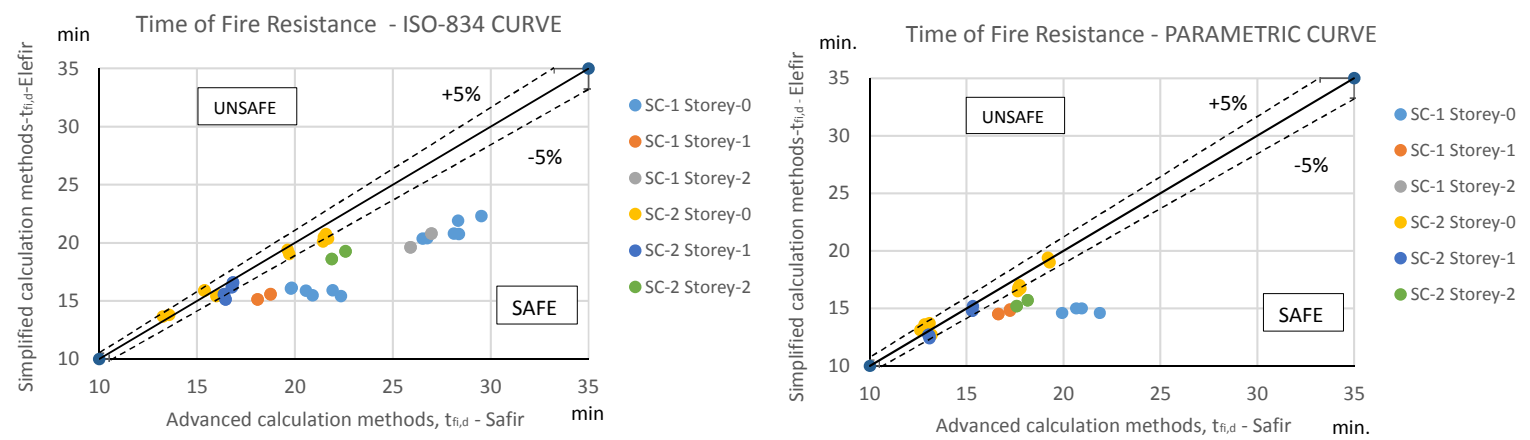

Fig. 5 Results of safety verification in a fire situation (simplified vs. advanced calculation method for standard and natural fire)

It is observed in Fig. 6, for both fire curves that the simplified calculation methods are within a safe range of $5 \%$ when they are compared to the advanced calculation methods.
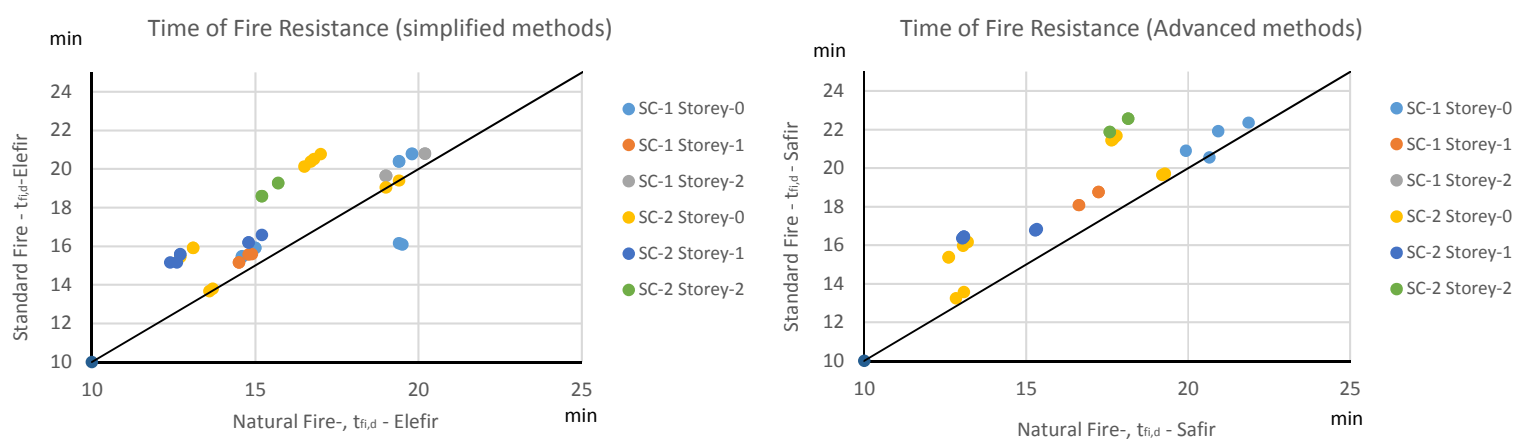

Fig. 7 Results of safety verification in a fire situation (standard fire vs natural fire)

Fig. 7 shows that for the analysed frames, and for the considered scenarios, both the simplified calculation method and the advanced method, in most cases, the standard fire curve ISO834 gave higher fire resistance time when compared to the natural fire. This is mainly due to the fact that the 
evolution of the temperatures in the cross-section is faster in the natural fire than in the ISO834 (see Fig. 3) and thus the critical temperatures are reached for lower times. The next step of this work will be to protect the structures for the required standard fire resistance and for the parametric fire curves and compare the results obtained with the simple and advanced calculation methods.

\section{CONCLUSION}

During a fire, high temperatures reduce the strength and rigidity of steel thus affecting the load bearing capacity of the frames. The structural designer must evaluate properly the behaviour of its elements in a fire situation, trying to be as realistic as possible.

For the cases studied, it can be concluded that:

i. To verify the resistance requirements for standard fire and natural fire, analysis of the elements is sufficient with the simplified calculation method within a safe range of $5 \%$ when compared to the advanced calculation method;

ii. The buckling coefficients proposed in (Couto et al. 2013) presented satisfactory results, therefore, both for the standard fire and for the natural fire, the simplified calculation method gave values close to those with the advanced calculation method, and mostly in favour of safety;

iii. Finally, in most cases it was found that for the considered scenarios, both the simplified calculation method, as well as the advanced calculation method, the standard fire gave higher resistance time.

\section{REFERENCES}

CEN, 2002a. EN 1990 - Eurocode - Basis of structural design.

CEN, 2002b. EN 1991-1-2, Eurocode 1: Actions on structures - Part 1-2: General actions - Actions on structures exposed to fire.

CEN, 2005a. EN 1993-1-1, Eurocode 3: Design of steel structures - Part 1-1: General rules and rules for buildings.

CEN, 2005b. EN 1993-1-2, Eurocode 3: Design of steel structures - Part 1-2: General rules - Structural fire design.

Couto, C., Vila Real, P., Lopes, N., Rodrigues, J. P., 2013. Buckling analysis of braced and unbraced steel frames exposed to fire. Engineering Structures, 49, pp.541-559.

Franssen, J.-M., 2005. SAFIR: A Thermal and Structural Program for Modeling Structures Under Fire. Engineering Journal, A.I.S.C., 42(3), pp.143-158.

Computers and Structures Inc., 1995. SAP2000 v14.0.0 : integrated software for structural analysis and design, Berkeley Calif.: CSI.

Vila Real, P. \& Franssen, J.-M., 2011. Elefir-EN V1.4.5 (2011), Software for fire design of steel structural members according the Eurocode 3. http://elefiren.web.ua.pt .

Vila Real, P., Couto, C., Lopes, N., Rodrigues J. P., 2010. Stability Check of Steel Frames Exposed to Fire. Structures in Fire: Proceedings of the 6th International Conference. Michigan, USA.

Xu, L., Zhuang, Y., 2014. Stability of Unbraced Steel Grames with Fire-Protected Columns Subjected to Elevated Temperature. In Eurosteel 2014, 7th European Conference on Steel and Composite Structures. Napoli, Italy. 